Revue d'histoire de l'Amérique française

ZWB REVUE D.HISTOIRE DE L'AMÉRIQUE FRANÇAISE

\title{
Lettre de Mme Sophie Nelson Brosnan à M. L.-O. David, re : Docteur Wolfred Nelson
}

Volume 17, numéro 1, juin 1963

URI : https://id.erudit.org/iderudit/302257ar

DOI : https://doi.org/10.7202/302257ar

Aller au sommaire du numéro

Éditeur(s)

Institut d'histoire de l'Amérique française

ISSN

0035-2357 (imprimé)

1492-1383 (numérique)

Découvrir la revue

Citer ce document

(1963). Lettre de Mme Sophie Nelson Brosnan à M. L.-O. David, re : Docteur

Wolfred Nelson. Revue d'histoire de l'Amérique française, 17(1), 104-106.

https://doi.org/10.7202/302257ar d'utilisation que vous pouvez consulter en ligne.

https://apropos.erudit.org/fr/usagers/politique-dutilisation/ 


\section{DOCUMENTS INÉDITS *}

A propos du patriote Wolfred Nelson (Copie de cette lettre nous a été fournie par Mme Jeanne Girouard-Décarie qui la tenait de Madame Hercule Lefebvre, petite-fille de Madame Brosnan).

\section{LETTRE DE MADAME SOPHIE NELSON BROSNAN}

À M. L.-O. DAVID

L'Honorable L. O. David,

Québec 21 Mars 1906.

Sénateur,

Cher Monsieur,

Ottawa.

Il y a déjà longtemps que je me proposais de vous écrire au sujet de deux faits dans l'histoire de mon père, le Dr. Wolfred Nelson, vous sachant si sympathique au mouvement auquel il prit part en 1837, et ayant lu avec beaucoup de plaisir quelques uns de vos intéressants écrits sur ce sujet.

Je suis la fille ainée du Dr. Nelson et j'avais quatorze ans lors de la bataille de St Denis. C'est vous dire que je ne suis plus jeune, et je désire pendant qu'il m'est encore possible de le faire, signaler à votre attention d'historien deux impressions fausses qui paraissent avoir cours en rapport avec cet évènement. Je vous parlerai d'abord de la mort de ce pauvre Ovide Perrault. Et il faut que je vous dise ce qui m'a subitement déterminée à mettre à exécution le dessein que j'entretenais de vous écrire. Aujourd'hui, vous le savez, les cartes postales illustrées sont un grand moyen de vulgarisation. Or, figurez-vous que j'ai reçu ces jours derniers une carte-postale contenant une vue de St. Denis, et cette indication: "La personne au milieu de la rue indique l'endroit où est tombé Ovide Perrault, blessé mortellement par une balle Anglaise, le 23 novembre 1837. Ce dernier allait transmettre un ordre du Dr. Nelson à des patriotes retranchés plus loin."

\footnotetext{
* Voir notre Revue, XVI: 117-126, 267-272, 436-440, 581-584.
} 
Cette carte m'a beaucoup peinée et j'ai résolu de ne plus tarder à vous écrire. Maintes et maintes fois j'ai entendu mon regretté père parler de la mort tragique de M. Perrault; à un moment de la bataille, M. Perrault attira son attention sur quelques hommes qui lui semblaient s'exposer inutilement, lui disant qu'il allait les avertir de leur danger. Là-dessus, mon père lui dit: "Non, non, Perrault, n'y allez pas, je vous le défends". Mais je vais courir" - "N'y allez pas, vous êtes un homme mort si vous le faites; je vous le défends." Mais l'héroïque jeune homme n'écoûtant que son grand cœur, ne voulut rien entendre, et s'élança. Combien de fois j'ai entendu mon père, parlant de ce triste incident d'une journée glorieuse, s'écrier: "Pauvre Perrault ! brave jeune homme ! si seulement il avait voulu m'écouter, il vivrait peut-être aujourd'hui." Vous pouvez comprendre, cher monsieur, quelle douleur c'est pour moi de voir se propager l'erreur historique que fait peser sur la mémoire de mon père la responsabilité d'une mort qui n'a eu pour cause que la seule bravoure et l'héroïsme de la victime elle-même.

L'autre chose dont je voulais vous parler est l'accusation faite contre le Dr. Nelson d'avoir provoqué les habitants à la révolte. A ce propos, laissez-moi vous raconter un fait dont j'ai été témoin, un peu après l'assemblée des six comtés tenue à St. Charles. Un dimanche, comme je sortais de l'église avec ma mère, après la grand'messe, nous aperçumes le Dr. Nelson sur le "hustings" entouré d'une foule considérable. Nous nous approchâmes. Mon père leur disait que des mandats avaient émané contre lui et les autres hommes publics qui avaient pris part à cette assemblée, et leur disait: "Mes enfants (c'était sa manière ordinaire et paternelle de leur parler) on viendra m'arrêter; laissez faire et que chacun de vous reste chez soi." La foule interrompit avec des cris "Non, Jamais ! nous serions des lâches ! Hourra pour le Dr. Nelson, notre père", \&c: \&c., "mais vous n'êtes pas armés" - "Oui, nous le sommes, nous avons des fusils." - "Mais ils sont rouillés." "Nous les fourbirons, et nous avons des fourches", \&c. C'était une clameur assourdissante qui s'élevait de cette réunion de braves et nobles patriotes. - "Ecoutez", reprit mon père, "il y aura du sang de versé et vous ne pourrez pas réussir. Restez chacun chez vous. Ils viendront me prendre, m'emmèneront avec eux et je leur expliquerai les raisons de ma conduite." - Mais tous les efforts de mon père pour les convaincre furent inutiles. Leurs cris s'élèvèrent d'avantage, pendant qu'ils protestaient qu'ils ne souffriraient jamais qu'il fût arrêté. Ce ne fut qu'en face d'une telle détermination qu'il fallut organiser une défense. Je n'ignore pas le discours du Dr. Nelson à l'assemblée de St Charles. 
Ça été le cri d'indignation d'un homme passionné pour la justice, et qui, anglais lui-même, se déclarait contre les siens pour une race opprimée qui n'était pas la sienne, mais qu'il aimait; mais comme il l'a déclaré à ses concitoyens de St. Denis, ainsi que je viens de le raconter, il eût préféré se sacrifier luimême et éviter un conflit entre eux et les représentants de l'autorité.

Il y a un autre point sur lequel je ne dirai qu'un mot. Plusieurs ont beaucoup reproché à mon père d'avoir refusé de prendre part au nouveau soulèvement de 1838, et de s'être par la suite séparé de ceux qui voulaient continuer la lutte et amener des résultats, vous savez lesquels, qu'il ne pouvait approuver. A son frère le Dr. Robert Nelson, qui l'invitait à se joindre à lui, il a répondu que c'était chose absolument inutile, et que cette tentative ne pouvait qu'entraîner des conséquences désastreuses. Puis il était d'avis que les concessions arrachées au gouvernement et les droits accordés aux Canadiens Français répondant aux demandes faites et qui avaient d'abord été repoussées, il convenait de s'en tenir là.

Il se peut, cher monsieur, que vous écriviez encore sur l'histoire de notre cher pays; j'ai cru que vous aimeriez avoir alors ces quelques notes devant vous et que votre esprit impartial saurait s'en servir de manière à rendre justice à un homme qui a tant aimé les Canadiens-Français. Mais vous dirai-je toute ma pensée ? Je ne connais pas de plume plus autorisée que la vôtre, ni de voix qui fût mieux écoutée sur ce sujet. J'ose donc espérer que d'ici peu vous saurez trouver l'occasion de faire connaître surtout les paroles que mon père a prononcées à l'endroit de cet héroïque et infortuné Ovide Perrault et de la défense organisée à St. Denis.

Veuillez croire, cher Monsieur, à la reconnaissance anticipée et aux meilleurs sentiments de votre dévouée,

(SOPHIE NELSON BROSNAN) 